\title{
Behaviour and Misbehaviour of Latino Children in a Time of Zero Tolerance: Mothers' Views
}

Judith K. Bernhard

Ryerson University

Marlinda Freire

University of Toronto

Luz Bascunan

Catholic Children's Aid Societies of Toronto

Rodolfo Arenas

York Community Services

Nury Rugeles Verga

Delta Childcare Services

digital.library.ryerson.ca/object/230

Please Cite:

Bernhard, J. K., Freire, M., Bascunan, L., Arenas, R., Verga, N. R., \& Gana, D. (2004). Behaviour and misbehaviour of Latino children in a time of zero tolerance: Mothers' views. Early Years, 24(1), 49-62.

doi:10.1080/0957514032000179052

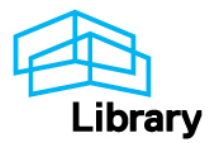




\title{
Behaviour and misbehaviour of Latino children in a time of zero tolerance: mothers' views
}

\author{
Judith K. Bernhard, ${ }^{\star 1}$ Marlinda Freire, ${ }^{2}$ Luz Bascunan, ${ }^{3}$ \\ Rodolfo Arenas, ${ }^{4}$ Nury Rugeles Verga ${ }^{5} \&$ Daniel Gana ${ }^{3}$ \\ ${ }^{1}$ Ryerson University, Canada; ${ }^{2}$ University of Toronto, Canada; ${ }^{3}$ Catholic Children's \\ Aid Societies of Toronto, Canada; ${ }^{4}$ York Community Services, Canada; ${ }^{5}$ Delta \\ Childcare Services, Canada
}

Thirty-eight Latin American mothers with young children tell of their perceptions of school discipline and comportment issues and talk of their children's encounters with 'zero tolerance' legislation, and related rules for conduct, implemented by the local school boards. The purpose of this exploratory study is to understand: (a) parents' views of and concern about disciplinary practices at school; (b) parents' ideas about the connection between home and school discipline; and (c) parents' understanding of the officially prescribed consequences of behaviour identified as non-tolerable. Implications of the findings are discussed with regard to professional practice.

Keywords: Latino parents; School regulations; Concepts of misbehaviour and aggression

\section{Introduction}

The dream of a better life has always lured immigrants to North America, where many minorities have achieved visible financial and social gains. Yet some minority groups and their children are being left behind, as measured by such indicators as graduation from high school and placement in gifted education (Chavkin, 1993; Ornstein, 1997; Gibson, 2002). Many of these are immigrant children whose parents have not finished high school, and this pattern is known to persist. School success fails to occur for a number of reasons. An indicator of minority problems is the disproportionate rate of identified special needs in the schools.

The most typical reasons for referral to special education are known to be reading difficulties and behavioural problems. A National Academy of Sciences study (Donavan \& Cross, 2002) found that although state-of-the-art interventions in reading and classroom management are effective, there is little evidence that most poor or minority children have access to such programmes. Instead, they are assessed and commonly directed to academic or behavioural special classrooms.

${ }^{\star}$ Corresponding author: School of Early Childhood Education, Ryerson University, 350 Victoria Street, Toronto, Ontario, Canada M5B 2K3. Email: bernhard@ryerson.ca 
The present study is focused on the issue of Latino mothers' and teachers' perceptions of young children's discipline problems and the reasons for the apparent lack of congruence between the two views. Of course, there is sometimes agreement about noteworthy infractions, yet differences emerge over some basic issues such as how offences are defined and adjudicated. Among the reasons for these difficulties, cultural differences may play a large role, in the view of the participants (see Suarez-Orozco, 1989; Diaz Soto, 1997; Damaris et al., 1998). In many cultures, there are specific kinds of behaviour that are not socially accepted as well as those that are. For example, in some Latino communities, there is tolerance of fighting and rough housing among children, where there are no injuries.

The present investigation is part of an effort to shed light on cultural differences as they manifest in one area of interaction between minority families and schools.

\section{Demographic and educational statistics}

The proportion of minority children to all school age children is now at 35\% in the US (Donavan \& Cross, 2002) and 13\% in Canada (Statistics Canada, n.d.), a dramatic increase in the last 20 years. Many children of minority groups are firstand second-generation immigrants, and these children are one in five of all children; there are over 14 million immigrant children in the US (Rumbelow, 2002).

Latinos, one of the fastest growing ethnic groups in the US and Canada, are receiving attention because of a number of school-related issues. In the US, Hispanics now number 35.3 million. For example, in the Washington area, the Latino population has risen $346 \%$ in the last two decades. In Canada, people with Spanish as a mother tongue increased from 70,000 in 1981 to 212,800 in 1996. Latin Americans in Canada, considered as a group, suffer from low academic achievement: only $65 \%$ obtain a high school diploma and university graduates account for only $10 \%$ of this group (Ornstein, 1997). One study (Drever, 1996; see also Brown, 1994) documented how rapidly Latino students became disengaged from a Toronto high school. In the US, similar phenomena have been reported for Latinos as a group (Donavan \& Cross, 2002). Problems arise, however, in the earliest years because of the deep roots of misunderstanding that are examined in this paper.

The millions of families classified as Latinos or Hispanics according to census self-descriptions are, in many ways, a heterogeneous group, and a number of demographic categories cut across the Hispanic classifications. For instance, a number of Hispanics are Black (cf. Cruz-Janzen \& Wardle, 2003). There are differences according to country of origin and perhaps more importantly, according to class and time of migration. We follow the path of several earlier researchers and educators, however, in presuming that the construct 'Latino families' is important in understanding a number of school issues, including general underperformance of the groups so designated (Gallimore \& Goldenberg, 1995; Drever, 1996; Gibson, 2002). The approach is no different, in principle, from the grouping proposed in studies of the school issues of Black or African American children, insofar as possible heterogeneity is concerned. Indeed, a significant proportion of Black Americans are 
Hispanic, in terms of culture. Following Darder et al. (1997) we construe Latin Americans as an ethnic group; the label Latino/Latina, here, is interchangeable with Hispanic and Latin American. We are proposing shared language, history, and culture as specific characteristics of this ethnic group, along with intra-group and extragroup perceptions. We are not proposing uniformity or 'same essence' for these persons; our grouping is to be justified only according to useful results, the same, for instance, as the category 'gas' in physics. In any given situation we do not exclude the possibility, that, on the evidence, some other variables are more important, or, in a word, that the proposed 'Latin American' grouping in a particular situation is too heterogeneous to work with. In the present case, aspects of the participants' heterogeneity are briefly discussed below as we explore the possible influence of other variables.

\section{A typical world view in Latino families}

Studies have reported that Latino families, although they exhibit great variety, typically adhere to a number of values that might be called traditional, in particular the role of authority figures and the concept of the collective family good and honour. In a study of Puerto Rican working-class mothers, Harwood et al. (1995) noted a primary cultural value of abiding by the laws of society which indicated that the cultural values are inherently more socio-centric than those of mainstream middle-class culture.

Several researchers have proposed the concept of attitudinal familism to distinguish Latino and Anglo families. The concept refers to the belief that relatives have more positive characteristics than non-relatives and is argued to be the most important factor influencing the lives of Latinos (Coohey, 2001). Although there are contradictory results on some aspects of familism, there are differences between acculturated and non-acculturated Latinos. One measure that distinguished Latinos regardless of acculturation is believing and feeling their kin are reliable sources of support (Sabogal et al., 1987).

Familistic values are those dealing with parental authority. An aspect of the authority issue is the amount of discussion. Latino parents do not believe that all their decisions should be discussed with the children and explained to them or, even further, that compromised agreement should be reached. The approach particularly applies to young children, who are not treated 'democratically.' The appearances here may remind one of what Baumrind (1971) called the authoritarian family. Further, one sees an absence of the give and take between parents and children that she attributed to healthy or authoritative families.

One of the reasons that labels like 'authoritarian' fail to be accurate is concerned with caring. Not unlike traditional parents from other groups, the rigour of parental discipline and demands is seen as a reflection of love for the children and a desire to minimize the pain that they will encounter in life. 


\section{Behaviour problems: violence at school}

Beginning in 1994, as a response to some extreme episodes of violence in US schools, there were federal safe schools laws, and subsequent to that, laws in all the states about school offences regarding weapons, drugs, and in many cases, other kinds of misbehaviours. Our search of the educational/social sciences databases revealed very few studies of this phenomena with young children and immigrants and virtually no studies with regard to Hispanic immigrant populations.

Polakow-Suransky's (2000) study, focusing on Michigan, looked at the effect of zero tolerance school policies on expelled children (ages 8-15) and their families. Often the offence was not well proven, and the rights of the children and families were ignored. In at least half of the cases, there was no place for the child to go. Some expulsions lasted an entire year or indefinitely, severely damaging or ruining a school career.

In Ontario (Canada), following a trend of increasing media attention to violence in schools, a Safe Schools Act was passed in 2000 that provided a clearly defined structure of punishments to be implemented by teachers and principals. The act provides for mandatory suspensions of up to 21 days for such medium-level offences as threats to inflict bodily harm, swearing at a teacher, or vandalism. Further, the act mandates expulsion for weapons-related offences and assaults causing bodily harm.

For disadvantaged groups from Latin American communities, the new rules in school discipline pose a difficult situation; parents in a large proportion do not have the knowledge and time necessary to respond to this very complex set of new rules and the quasi-legal nature of suspension and appeals. Thus, most suspensions and expulsions are uncontested, causing Latino children and youth, especially of the working class, to become even more disengaged and alienated. Even if, as in the case with young children, there is not an actual expulsion, labels of 'behaviour problem' or 'disorder' continue to affect the child's school career, often in a self-fulfilling fashion. The following questions provide a focus for the investigation:

1. To what extent do parents and teachers agree about disciplinary practices and significant infractions of discipline at school? The focus will be on key issues such as definitions of minor and major offences and application of fair adjudicative practices.

2. In terms of their culture, what are the parents' ideas about the connection between home and school discipline?

3. What is the nature of parents' understanding of the officially prescribed consequences of behaviour identified as non-tolerable?

\section{Method}

\section{Objective}

Given the dearth of established findings in the area, this study is viewed as exploratory. Our examination of the data is therefore oriented toward generating, 
rather than proving, hypotheses. We will be endeavouring to lay the foundations for further, more comprehensive, research.

\section{The team}

The Latin American Families Project is a three-year project that aims to find ways of supporting families in contributing to children's education. The interviews were conducted by Spanish-speaking senior members of the research team, all of whom hold at least a master's degree in the areas of education, health, and social work. Two of the team members were employed by the Children's Aid Society. Two worked in community centres in an area of high immigrant influx from Latin America. One team member, from Chile, completed postgraduate training in psychiatry, in Canada, and is a school board Chief Psychiatrist. Another team member emigrated from Chile at 16 years of age, and ultimately received her doctorate in education, in Canada.

\section{Participants}

The participants for the larger study were recruited through contact with community agencies. The criteria for participation were that the parents had arrived in Canada in the last 10 years and had at least one child under the age of 18 . We received the names of 100 families. All families whose members had not formally received professional services for psychological or emotional problems were invited to participate and none of them declined. We were able to complete interviews with 65 parents. We chose 38 of the parents, those with young children (4-9 years of age) as sources of data for this paper. The data for the older children are published separately.

The majority of the participants were between 25 and 44 years of age $(83 \%$, $n=32)$. Thirty-two were women, and in six cases, both mother and father participated in the interview. The majority of the participants were married $(73 \%, n=28)$, and the majority of them $(60 \%, n=23)$ had acquired education beyond high school. The mean time they had been in Canada was 6.2 years. The sample included parents who emigrated from Mexico, Central and South American countries to Toronto (Chile, $n=7$; Colombia, $n=6$; Ecuador, $n=6$; Argentina, $n=6$; El Salvador, $n=5$; other, $n=8$ ). Further demographic information is shown in Table 1 .

\section{Procedure}

Each family was interviewed by a senior member of the research team in face-to-face interviews that lasted between two and four hours. The interviews were in Spanish and conducted at the family's home or at the local community centre. At the beginning of the interview, we explained that the purpose was to understand the children's situation in the school. Questions or topics introduced focused on first-hand experiences. Our phrasings were open-ended, for example: Who here at home is in charge of communicating with the school? When the child has a serious problem 


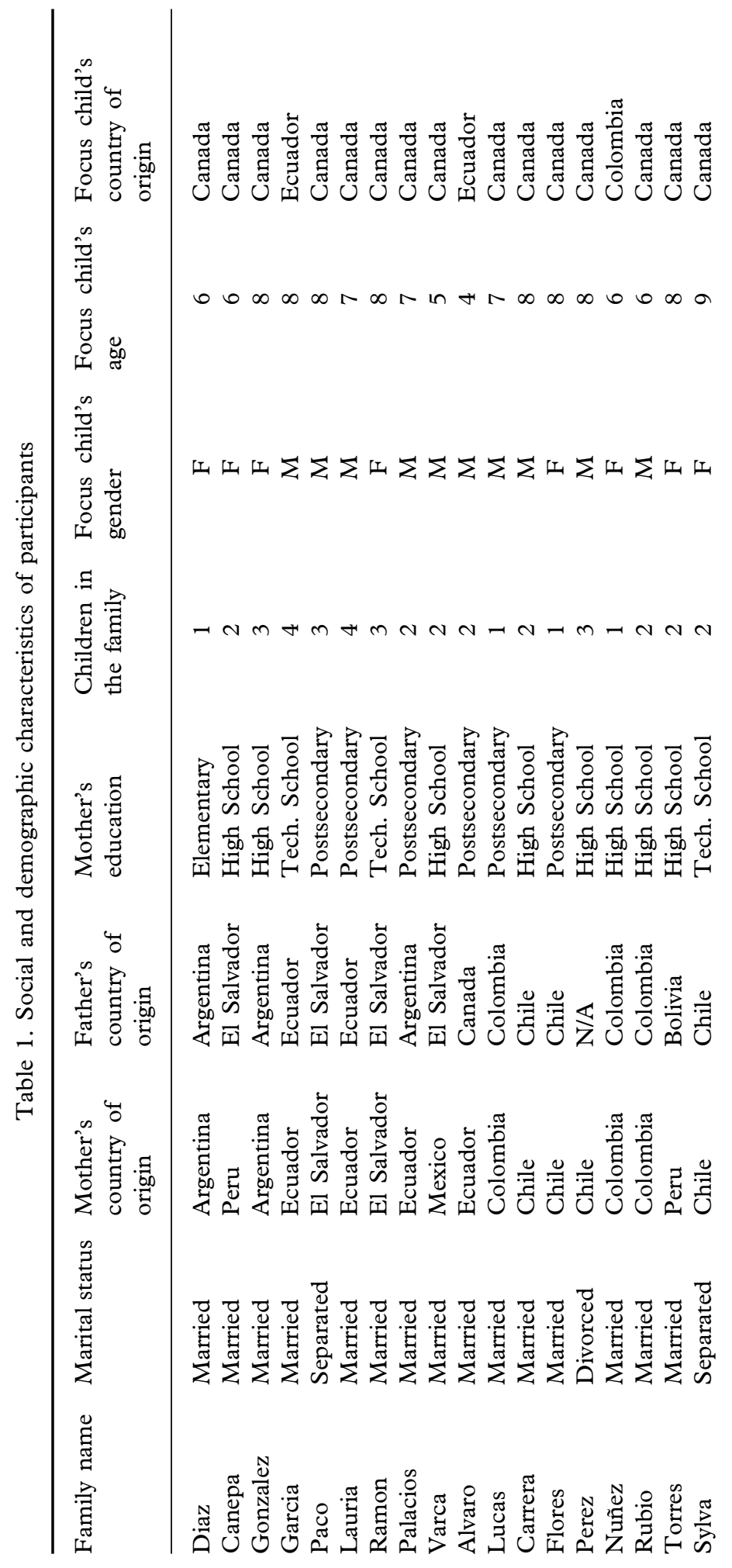




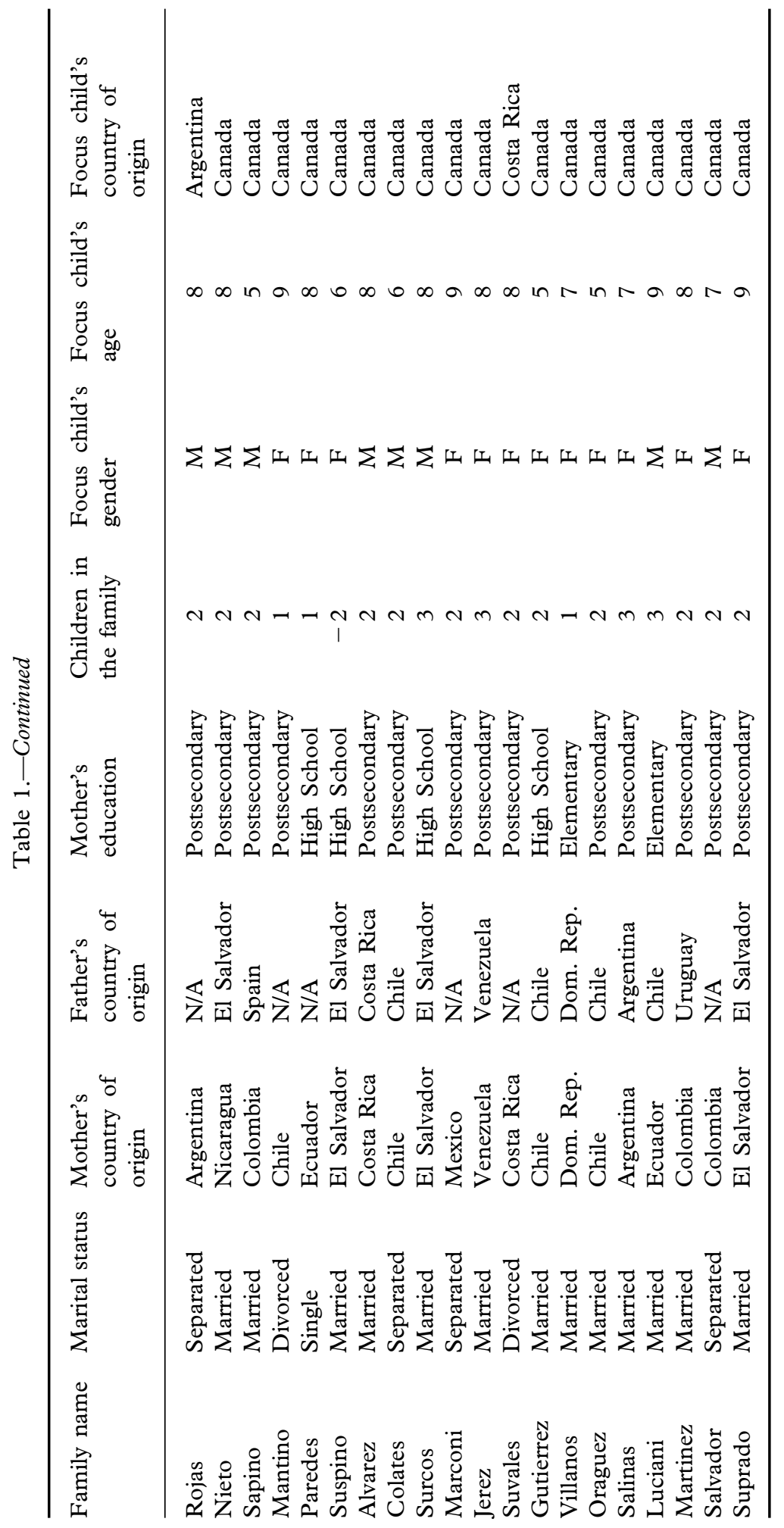


at school, who takes care of it? Using neutral wording, we asked about the parents' impression of the school's discipline, if any, in relation to the child. Further, we probed specifically for any cases of disagreement with the school and attempted to form an idea of the frequency and depth of disagreement or agreement. While we endeavoured to appear and be sympathetic, we did not indicate an opinion of the disagreement or of our view of its resolution.

Additionally, parents were asked to show us documentation from the school, including report cards and to explain their content. Behavioural observations from these documents were recorded.

After trust was established and permission granted by the family, the interviews were audio-taped. A bilingual translator transcribed the interviews, and these were reviewed and corrected. Following procedures for qualitative data analysis (Denzin \& Lincoln, 2001), team members read and re-read the transcripts and developed codes and categories according to the themes that emerged. Here, we report three major findings.

\section{Results and discussion}

Finding 1: Parents perceive teachers as being overly bureaucratic, impersonal, arbitrary

The parents expressed great concern over the teachers making decisions too quickly without looking at who is involved, previous history, possible reasons, context, and possible consequences of the teacher's decisions. Mrs Garcia [all names are fictitious] emigrated from Ecuador six years ago with her four children where she worked as a seamstress. Her eight-year-old son has attended the same school since Grade 1. Mrs Garcia told us how upset she was that her son had been punished for a minor offence at a time when he was to have been rewarded for great academic efforts that resulted in an award.

[The children in my son's class] had being working on a project outside the classroom. The young boy who was bothering [my child] kept coming by, saying bad words, insulting [my child], so my son hit him. In deciding to suspend him [my son], the principal did not consider the witnesses or that it was my son's first offence of this type. This was the day they were giving diplomas to the best students of the month, and one of them was my son. He did not receive the diploma.

A number of parents reported feeling that teachers were not interested in the child as a person, but were simply complying with absolute rules and regulations. The case of Mrs Rojas demonstrates a scenario where her seven-year-old son recognized he had acted badly in swearing to a teacher under his breath and apologized to the school. The parents also agreed that he should be punished but could not understand why the school would not be more caring about the child's academic future.

Alfredo was suspended from school. We [with ex-husband] went to talk to the vice-principal and told him that he [the child] recognizes he acted badly, but not to suspend him because he was going to lose the school year. We asked if the child could do some volunteer work as a penalty. The vice-principal was totally against it and said that in this school there is no volunteer work ... So we could not do anything. They 
don't care about the student as a person, they are only following rules ... How can they be so rigid?

Alfredo eventually was sent to work with his father as the parents implemented their own volunteer work programme.

In their desire for educational processes not to be impersonal, some parents had a belief in the usefulness of warmth and nurturing behaviour on the part of teachers. They believed the children's misbehaviour was partly due to the teachers being indifferent, cold and impersonal. They felt that children needed more humanity to be motivated to behave well.

When she lived in Peru, Mrs Torres was a social worker who had a great deal of contact with children and families. She now lives in Canada working as a cleaner and doing her best to support her husband (currently unemployed) and their eight-year-old daughter.

\footnotetext{
Teachers should be more conscious that we are trying to raise our children differently than they are used to. They are very indifferent, they are very ... don't give them the warmth, love that one would expect from a teacher because they should be like second parents.
}

Discussion of finding area 1. The Latino mothers we interviewed expected the school to be more than just an efficient place of business (or service delivery), but also to have a familial aspect as the context for shaping children. The bureaucracy, with its complicated rules, was seen as inhumane. Latino mothers expected the teachers not just to be bureaucratic, precise, rule followers, but to also be human, to look at each situation in context, and to have a heart in deciding what is best for the particular child.

For most mothers, the exercise of discipline is connected with the parents' love and concern for their children, especially the young ones. A frequently expressed sentiment was 'If you love your children, you will discipline and control them to keep them from going astray.' In the schools' contrasting position, discipline is to the letter of the law and characterized by apparently impersonal behaviour from staff and teachers.

It is perhaps surprising to see teachers' bureaucratic, impersonal approaches mentioned by parents. Teacher training programmes have been explicitly child centred for several decades. At the same time, however, teachers may have been distracted by increasingly complex sets of rules, regulations and procedures they must follow.

Finding 2: Parents and teachers do not distinguish major and minor misbehaviour in the same ways. Parents downplay verbal exchanges and don't agree with a legalistic or 'zero tolerance' approach

School examples of rigidly enforced rules included such statements as 'Aggressive behaviour will not be tolerated,' or 'In children's interactions, the application of 
physical force, no matter how minor, is never appropriate.' Parents felt that schools exaggerate, that the nature of kids is to be rambunctious, this is 'conducta normal.'

Mrs Paredes emigrated from Chile as a travel agent but is currently not employed. Her views on the school's reactions to her eight-year-old daughter are representative of many of our mothers:

\begin{abstract}
My daughter was being excluded from her group of friends so she took one of the girls and started to shake her. The girl [who was shaken] and another girl [who was part of the group] started crying and my daughter was sent to the office. This was the first incident of this kind for her. The school clearly showed her that she should keep her hands to herself. They told her that if it happened again, they would suspend her. It seems to me they were too drastic because in our culture these things get resolved between the children. But the school, I think, was very drastic and from then on there was a distance between us and them.
\end{abstract}

Mrs Nuñez was a hairdresser in her native Colombia. She now lives in the basement of her brother's home with her six-year-old daughter. Mrs Nuñez provides a clarification on the differences between major and minor misbehaviours, and similar views were expressed by the parents of younger children:

American children are calmer, I don't know if it is because of the way they are raised but Latino children are more effusive. If you see a child running, kicking a ball, moving around from one place to another, with the shirt open, the tie hanging to the other side, we see this as normal whereas Canadian children are more passive.

Discussion of finding area 2. As noted above, principals are charged under the Safe Schools Act and with the legal duty to ensure safety at their schools and give each child a safe learning environment. Further, these educators typically believe that the most minor signs of aggression predict later problems and must therefore be dealt with on a zero tolerance basis. Accordingly, at many schools there are said to be no 'minor' offences. The enforcement against 'violence,' including for instance 'pushing,' was very strong. The mothers were disinclined to consult lawyers or litigate in a system perceived as unfriendly to their concerns.

For many of the mothers, a broad range of behaviour was tolerated as normal child's play: boys pushing each other or pulling a girl's braids would be seen as expected behaviour among children. Major categories of misbehaviour would be those which undermine or disrespect authority. The schools' zero tolerance policy on aggressive behaviour at school dictates that there are few or no minor offences. Hence a shove, as much as a punch, is an assault. A general view among our families was that schools often make mountains out of molehills.

There have been cross-cultural studies comparing the development of aggression in young children (Triandis, 1994). Recently, La Freniere et al. (2002) reported a finding of decreasing aggression from 3-6 years of age in samples of children from Austria, Italy and US but not in those from China, Japan, and Russia; they conceded, '...what might be considered as a universal developmental pattern by North American researchers is perhaps specific to Western cultures' (p. 214). 
Finding 3: Schools and teachers do not set up an adequate training and discipline system, one that would be continuous with the system in place at home. They are overly tolerant and lax in response to moral conduct type issues

Many parents felt that the schools expected the impossible from them. They were puzzled as to how they could set up an effective and strict system at home if the rules at school were so lax. Parents were getting the message that they need to do more at home to get the child to behave, but felt it could not be done on their own since rules need to be followed up both at home and at school in order to work. Mrs Sylva, a secretary who emigrated from Chile, talks about her situation with her 9-year-old son.

I have had problems, for example, with my boy at the school. They say he has behaviour problems so I constantly have to be going to the school to talk to the teacher and to put things in order. Many times I have to get mad with the teacher so that she helps me, because if she does not help me, I can't do everything at home alone with the child.

Parents were concerned that schools are not teaching children to be respectful and this has great consequences for what they feel is acceptable. Children at school should be required to be polite. Mrs Ramon was a bank teller in her native El Salvador. She now works as a cleaner in Canada where she lives with her husband and three children, including an 8-year-old daughter.

In my country, children say hello, good afternoon, how are you. Education is more than reading words ... the rules of courtesy are important for [schools] to impose. Here ... [children] don't even say hello to the teachers in the school, many times they just talk any way they want ... [teachers] don't require the children to show them any respect.

Discussion of finding area 3. While it might seem inconsistent to call for a laissez-faire, non-legalistic approach on the one hand and strict punishment on the other, parents believe that the schools, besides protecting children from danger, should also morally shape the children's character. They view teachers as functioning 'in loco parentis' with many of the same responsibilities as parents.

The mothers we interviewed saw discipline as having certain prerequisites, among them the children's learning to show respect to adults and authorities, beginning in the earliest years. Where schools seemingly ignore this issue in favour of simple rule following, the mothers viewed the system as inadequate. These attitudes underlie the preference of many Latino parents for enrolling their children in Catholic schools even when they are non-practising or not Catholic. Parents see proper character development as based on good demeanour, which is inherently relational (Harwood et al., 1995; Bernhard \& Freire, 1999). Examples of good demeanour include knowing when to act affectionately and when to be ashamed for oneself and for others ('verguenza ajena'). The learning of 'shame' is especially important in four- to eight-year-olds; the beginnings of this emotion are generally said to be in those years. From the schools' point of view, the rules and procedures are aimed to 
develop the whole child, but because of the neglect of issues of demeanour and the emphasis on rules, parents may simply find the schools are inadequate in key areas.

It will help to explain this finding if we consider the typology proposed by Baumrind (1971) that has greatly influenced educators' thinking. There appear to be cultural differences in the conception of what parental love involves. In a North American setting, emphasizing the child's individualism, parents exhibit their love in affirming the child's individuality and accepting his or her unique deviations from uniformity. Even pre-school children are taught that they have a say, for example, about food, which should be carefully heeded by parents and, by extension, all adults. The mothers in our sample, by contrast, saw this kind of love as uncaring or neglect. The parents saw their mandate as one of shaping children's character and behaviour in a strict but loving way from the earliest years (similar findings: Gallimore \& Goldenberg, 1995; Bernhard et al., 1998). Thus there can be no simple way to provide continuity between the liberal school and the traditional Latino family.

\section{General discussion}

As professionals in the educational system and as educators of teachers, we do, of course, have opinions about many practices occurring in the educational system especially with regard to immigrant families. We are not necessarily in agreement with the mothers' perceptions or evaluations in a number of areas. Although here we have focused on the parents' views, we appreciate the presence of a variety of viewpoints on the issues. In most cases, we believe our personal views are more nuanced and less black and white than those of many participants. We would hardly call teachers 'arbitrary' or 'impersonal.' Nor are they, as claimed, ill-intentioned in a number of incidents. For example, parents often viewed the teachers as intentionally disturbing family life by telling children to call emergency services at the drop of a hat. Yet we regard this at best as a serious misperception of what happens in the classroom. Overall, we believe that we have treated the participants' views as their perceptions and have written them up accordingly. Our findings then are reports of perceptions and are not necessarily endorsed by us as the only truth about the reality at schools.

Although these families did not lack disciplinary problems (defined in their own terms), they appeared generally to be functional, with adequate controls that were, in our opinion, not unduly harsh. Hence one can inquire, more broadly, into the source of difficulties between school and family over discipline.

In connection with the 'impersonality' issues, as in Finding 1, for these Hispanic mothers, discipline always had a human face: father, mother, or respected elder. Further, the discipline and respect that were demanded were part of what might be called a protective covenant: the parents and senior figures provide and they shelter the family, especially the children, from the world's dangers. This context of discipline does not at all resemble that of the school: in many cases, the rules are an impersonal system that self-evolved; its enforcers need not be involved, any more than traffic police need to be focused on the rationale, for instance, of a speed limit, 
or on why, in any given case, it is being violated (e.g., emergency). The impersonal and the personal view, enacted in the school context simply cannot understand one another.

Consider the rule: you may not strike or shove anyone. These Hispanic mothers certainly did draw lines around 'assault' issues, but tended to look the context: child's play, horsing around, what kids of that age do, without particular malice. They would not incline toward taking legal action over a definition.

One may ask about the possible influence of class on this finding. While we did not separately analyse data in terms of class, we can give an impression of a rough correlation which we observed between tolerance of physical horseplay and middleclass status. We believe that the working mothers were generally more tolerant and our hypothesis would be that the lesser tolerance of middle-class participants is in some measure due to their being assimilated into mainstream Canadian life.

In finding out what the mothers think, one cannot claim that we have a full picture of the views of all important adults in the children's lives. We do know what mothers say when interviewed alone, but do not know what fathers would say alone. We do know most of the couples tended to agree with each other, but do not know what differences, if any, underlie the agreement.

Present-day schools face an enormous problem, given student diversity. Introducing detailed rules that apply to all, might seem an appealing answer. If there is uniformity, the school can run more smoothly. Yet careful and fair application of rules, and the fruits of a given disciplinary approach also require consideration. Even where the school rigorously provides a safe, orderly environment, without 'incidents,' the family will be looking for the normal requirement of authority, which is to say, respect. And at least in the family's perceptions, it will be absent, despite the rule-following, in the cultural context we have described. The school will be seen as having abdicated a position in moral training, hence the common preference for a Catholic school.

There is no easy resolution to many of the issues. The school personnel need more than the 'cultural sensitivity' in which they may be trained. One may say that a deeper level of 'intercultural' skills and sympathetic understanding of alternate world views are required.

\section{Acknowledgements}

The data reported here are part of a larger study funded by the Center of Excellence for Research on Immigration and Settlement. We wish to thank the participating families as well as our colleagues, Michael O'Loughlin, Harold White and Veronica Pacini-Ketchabaw.

\section{References}

Baumrind, D. (1971) Current patterns of parental authority, Developmental Psychology Monographs, 4(1, Part 2). 
Bernhard, J. K. \& Freire, M. (1999) What is my child learning at school? culturally contested issues of Latin American children and families? Canadian Ethnic Studies Fournal, 31(3), 72-94.

Bernhard, J. K., Freire, M., Torres, F. \& Nirdosh, S. (1998) Latin Americans in a Canadian primary school: perspectives of parents, teachers, and children on cultural identity and academic achievement, fournal of Regional Studies, 19, 217-236.

Brown, R. S. (1994) A follow-up of the Grade 9 cohort of 1987 secondary students survey participants (Toronto, Toronto Board of Education).

Chavkin, N. F. (1993) Families and schools in a pluralistic society (New York, SUNY Press).

Coohey, C. (2001) The relationship between familism and child maltreatment in Latino and Anglo families, Child Maltreatment, 6, 130-142.

Cruz-Janzen, M. I. \& Wardle, F. (2003) Multiracial and multiethnic children in schools (Needham Heights, MA, Allyn \& Bacon).

Damaris, R., Carrasco, C. \& Charbonneau, J. (1998) The case of Central Americans living in Montreal (Toronto, Centre of Excellence for Research on Immigration and Settlement).

Darder, A., Torres, R. \& Guttierez, H. (Eds) (1997) Latinos and education: a critical reader (New York, Routledge).

Denzin, N. \& Lincoln, Y. (2001) Handbook of qualitative research (Thousand Oaks, CA, Sage).

Diaz Soto, L. (1997) Language, culture and power: bilingual families and the struggle for quality education (Albany NY, State University of New York Press).

Donavan, S. \& Cross, C. (2002) Minority students in special and gifted education (Washington, DC, National Academy Press).

Drever, N. (1996) Frustrated learners: an ethnographic study of Spanish-speaking students at an inner-city high school in Toronto. (Unpublished Master's thesis, University of Toronto).

Gallimore, R. \& Goldenberg, C. (1995) Immigrant Latino parents' values and beliefs about their children's education, Culture, Motivation and Achievement, 9, 183-225.

Gibson, M. A. (2002) The new Latino diaspora and educational policy, in: S. Wortham, E. G. Murillo \& E. T. Hamann (Eds) Education in the new Latino diaspora: policy and the politics of identity (Westport, CT, Ablex).

Harwood, R., Miller, J. \& Irizarry, N. (1995) Culture and attachment: perceptions of the child in context (New York, Guilford Press).

La Freniere, P., Masataka, N., Butovskaya, M., Chen, Q., Dessen, M.A., Atwanger, K. et al. (2002) Cross-cultural analysis of social competence and behavior problems in preschoolers, Early Education and Development, 13, 201-220.

Ornstein, M. (1997) Ethno-racial inequality in Metropolitan Toronto: analysis of the 1991 census, paper presented at the Urban Forum on Immigration and Refugee Issues, Toronto, Canada, February.

Polakow-Suransky, S. (2000) America's least wanted: zero-tolerance policies and the fate of expelled students, in: V. Polakow (Ed.) The public assault on America's children: poverty, violence, and juvenile injustice (New York, Teachers' College Press), 101-129.

Rumbelow, H. (2002, July 12) Study notes more children with immigrant parents: federal report cites health, educational concerns, The Washington Post, p. A2.

Sabogal, F., Marin, B. \& Otero-Sabogal, R. (1987) Hispanic familism and acculturation: what changes and what doesn't, Hispanic fournal of Behavioral Sciences, 9, 397-412.

Statistics Canada (n.d.) Population data. Available online at: http://www.statcan.ca/english/Pgdb/ People/popula.htm (accessed 16 September 2002).

Suarez-Orozco, M. M. (1989) Central American refugees and US high schools: a psychosocial study of motivation and achievement (Stanford, CA, Stanford University).

Triandis, H. C. (1994) Culture and social behavior (New York, McGraw-Hill). 